\title{
La extraña visita: por una teoría de los rituales amazónicos
}

\author{
Óscar Calavia SÁEz \\ PPGAS, Universidade Federal de Santa Catarina \\ occs@uol.com.br \\ Barbara ARISI \\ UNILA Universidade Federal da Integração Latino-Americana \\ barbara.arisi@gmail.com
}

Recibido: 10 de enero de 2013

Aceptado: 24 de enero de 2013

\begin{abstract}
RESUMEN
El hábito de entender el ritual como una representación de estructuras sociales y simbólicas lleva a dejar en segundo plano su eficacia simbólica y su eficacia social. O sea, su valor de «laboratorio» en que se ensayan nuevas relaciones entre sujetos o nociones. Por ello mismo los estudios sobre ritual suelen centrarse en aquellos que se consideran más «representativos», evitando aquellos que parecen informales o inauténticos, en especial los que caerían en una categoría espuria de «rituales para un público», o «para turistas». Una revisión de los rituales pano -y de los rituales amazónicos en general- revela, sin embargo, que las acciones rituales «para los otros» han ocupado desde siempre un lugar central, y que incluso en las versiones actuales más comercializadas se manifiesta el mismo impulso socializador e innovador (con un amplio margen para la improvisación) que siempre caracterizó a esas sociedades constitutivamente abiertas.
\end{abstract}

Palabras clave: Ritual, economía/comercio, improvisación, pano, Amazonia.

\section{The Strange Visitor: Towards a Theory on Amazonian Rituals}

\begin{abstract}
The habit of understanding «ritual» as a representation of symbolic and social structures usually leaves its symbolic and social effectiveness to the background, that is, its value as a «laboratory» in which new relations between subjects or new notions can be experimented. The studies on rituals tend to focus in those considered as more «representatives» and to avoid the ones that appear to be too informal or inauthentic, especially the ones that would fall into the spurious category of «ritual for the public» or «for tourists». A review of Panoan rituals -and the Amazonian rituals in general- reveals, nevertheless, that the ritual actions «for others» have always occupied a central place. And even in the more commercial contemporary versions they manifest the same socializing and innovative impulse (with its broad improvising margin) that have always characterize those constituently open societies.
\end{abstract}

Key words: Ritual, economy/commerce, improvisation, Pano, Amazon.

Sumario: 1. ¿Rituales? 2. Intercambios cósmicos. 3. La ayahuasca. 4. Eficacia ritual. 5. Referencias bibliográficas.

Giuseppe Bergman, protagonista de varios cómics del italiano Milo Manara, se encuentra con un indio en plena selva amazónica. Intenta presentarse, pero el indio le detiene en seco, advirtiéndole que el nombre personal nunca debe ser pronunciado, so pena de graves males. Se ofrece a darle un apodo que pueda usar sin peligro. Como el azar ha querido que lo encontrase andando a cuatro patas, le dice que de ahí en adelante le llamará «anda como un perro» o sea, en su lengua, Yusé-Pe. Giuseppe 


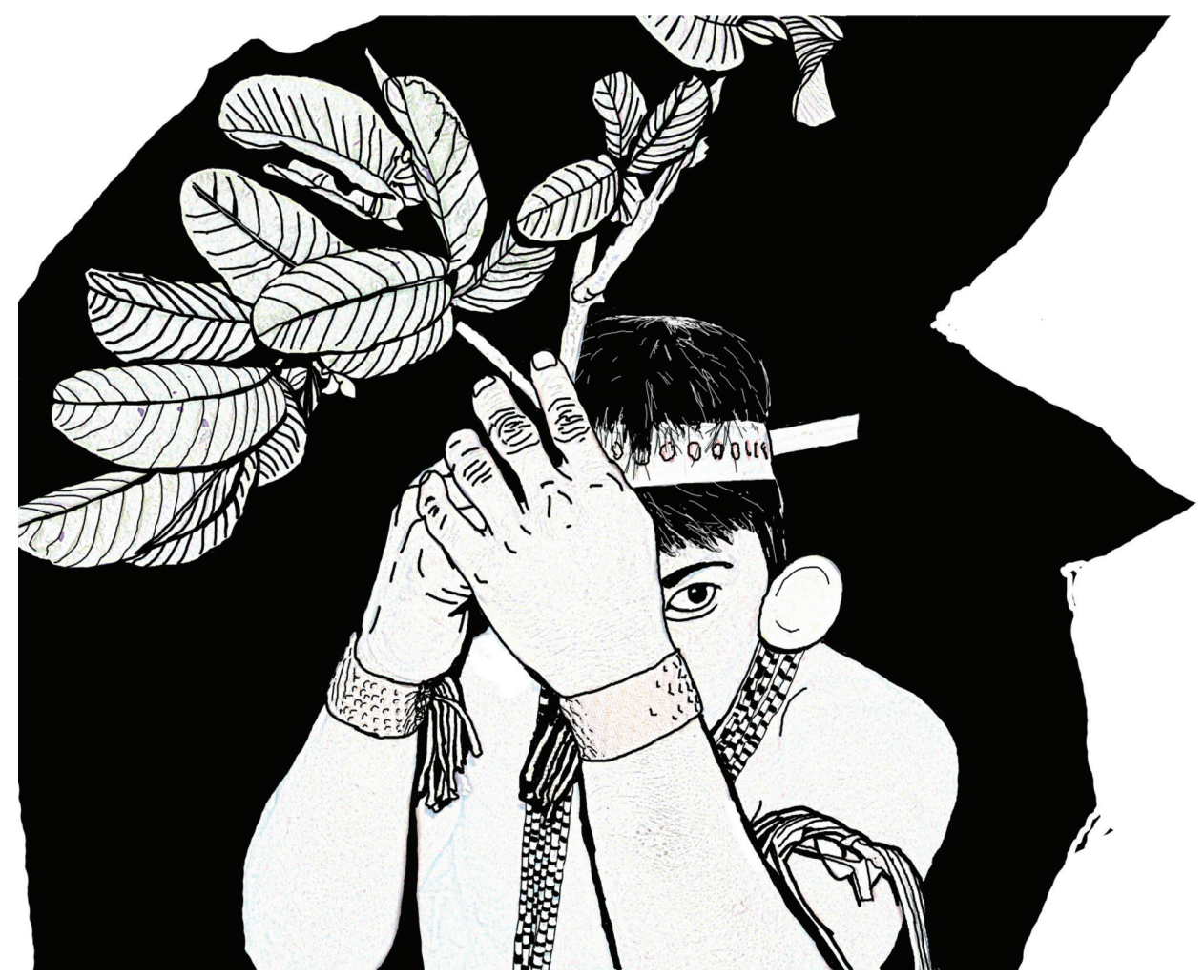

Figura 1: El maestro Makë Bëux inventa un pájaro en la nëix tanek. (Arte: Frank Koopman sobre foto de Barbara Arisi).

asiente: nunca tendrá cómo saber si respeta o no el tabú, pero al menos seguirá llamándose como siempre ${ }^{1}$.

La etnología amazónica se enfrenta constantemente a ese mismo tipo de dilema. Trata de culturas que han incorporado un gran volumen de elementos tomados del mundo de los blancos, al tiempo que abandonaban, visiblemente, las prácticas y los símbolos tradicionales: eso hace que se las interprete como conjuntos frágiles, que se desagregan a los primeros embates de una civilización externa, confirmando el pesimismo etnográfico que prevaleció hasta los años ochenta del pasado siglo. A no ser que, con esa incorporación, los indios estén reafirmando precisamente un patrón tradicional de captura y absorción de elementos externos, que ya se manifestaba antes de que llegase esa exterioridad a la que nosotros tendemos a dar tanta trascendencia. Siendo así, aquella famosa división de la historia indígena en un antes y un después de la llegada del blanco, marco común de los diagnósticos de la aculturación y el etnocidio, se habría

\footnotetext{
1 Citamos de memoria sin poder consultar la fuente. Los términos que Manara usa son otros, pero el chiste es eso mismo. Los indios amazónicos de Manara están inspirados en los yanomami, por su aspecto físico, los usos descritos y en particular por ese tabú referente al nombre; eran, en los años setenta, los indígenas amazónicos de más notoriedad en Europa.
} 
decretado sin la anuencia de sus principales afectados. Esa es la línea interpretativa más común en las últimas dos décadas, que, con un optimismo simétrico al pesimismo anterior, postula estructuras indígenas extremamente resilientes, capaces de «pacificar» o «domesticar al blanco» (Albert y Ramos 2002) o por lo menos de fagocitar su cultura.

Escoger entre aquel tipo de pesimismo y este tipo de optimismo no depende de los datos. Los yaminawa (Calavia 2002) dan a los blancos el nombre -nawa- que siempre reservaron a los extranjeros; sus mitos están cuajados de episodios que describen guerras con los nawa, lo que, cuando esos mitos son traducidos, da el curioso resultado de describir a los «blancos» armados de arcos y flechas y pintados para la guerra. ¿Los yaminawa ven blancos por todas partes o son incapaces de verlos en ninguna, reconocen o no algo radicalmente nuevo en su experiencia actual? El elemento de prueba es el mismo para una y otra posición. Si para Giuseppe Bergman no hay cómo diferenciar entre el respeto a la norma y su transgresión, puede ser que en el mundo amazónico no haya razones para contar con una frontera sólida entre un interior y un exterior, entre la tradición y la innovación. La polémica se salda, en realidad, por motivos políticos: hace tiempo que ha quedado claro que la noción de que los indios son capaces de sobrevivir al blanco ayuda, y mucho, a que de hecho sobrevivan.

Si ese uso de lo extranjero se manifiesta en el conjunto de cualquier cultura amazónica, lo hace muy particularmente en el ritual. Un extenso capítulo del ritual amazónico consiste en escenificaciones de la visita de extranjeros que comparecen con los más diversos propósitos: ofrecer o recibir regalos, flagelar a sus anfitriones para darles fuerza, ingerir comida o bebida hasta «morir», o transformarse ellos mismos en comida. Los rituales tupinambá más tempranamente registrados -la famosa salutación lacrimosa, o la llegada de los cautivos a las aldeas- se integraban en ese tipo. Rituales como el Pawana de los wai-wai (Howard 1993), el Nixi Pae de los kaxinawá (Lagrou 2007), la embriaguez forzada de los afines (Vilaça 1992), el de los pescadores visitantes enawene-nawe (Silva 1998), o los diversos del Xingu, de los cuales el más famoso es el Kwaryp (Agostinho 1974; Junqueira y Vitti 2009) -improvisamos aquí como mera ilustración una lista que podría hacerse interminable- escenifican la llegada de visitantes que encarnan una larga serie de formas y matices de la alteridad: pueblos aliados o enemigos; hombres blancos; animales, espíritus, antepasados, muertos. Formas de alteridad en gran medida intercambiables, sobre todo si, siguiendo interpretaciones perspectivistas (Viveiros de Castro 1996), se entiende que en todos los casos se trata del mismo tipo de sujetos, una especie de segunda persona del plural encarnada en naturalezas variables.

El análisis de ese tipo de ceremonias apunta, por lo común, a una actualización teatral de las nociones de alteridad e identidad de la sociedad indígena. Sugerir que su guión puede proceder de la práctica real de recibir la visita de extranjeros no pasaría, claro está, de una banalidad historicista; de hecho, y junto a los casos en que son habitantes de la propia aldea quienes hacen el papel de los enemigos o los espíritus visitantes, hay muchos otros en que los visitantes son, efectivamente, visitantes. En un caso o en otro, lo que interesa es la relación entre los ejecutantes concretos y las funciones simbólicas que incorporan. Pero quizás, en el otro extremo de esa banalidad historicista, haya una banalidad simétrica (sociologicista o estructuralista, tal vez) en suponer que el ritual deba consistir en una representación. 
Demos un paso más antes de volver sobre ese punto. Las funciones simbólicas representadas mantienen su privilegio incluso cuando el desempeño ritual es imprevisto e improvisado, o sea cuando quien está en escena no es ya un ejecutante ritual sino un agente histórico, que no sabe que sus acciones van a ser interpretadas como una especie de auto sacramental. Es el caso, claro está, del célebre episodio del capitán Cook cuya llegada fue interpretada por los hawaianos como una visita del dios Lono, un célebre caso antropológico que dio lugar a numerosas reflexiones de Marshall Sahlins y a una vasta progenie polémica (Sahlins 1985, 1995; Obeyesekere 1997; Borofsky 1996 [1987], 1997). Podría ser también el caso, tan semejante pero aún más dramático, de la interpretación-Quetzalcoatl de Cortés y sus tropas en los episodios iniciales de la invasión de México, que también ha hecho correr ríos de tinta, aunque no exactamente en torno de ese mismo argumento. Hablamos de episodios ajenos a la etnología brasileña y amazónica, pero hay que notar que el caso Cook-Lono ha sido constantemente invocado por los investigadores de la historia indígena en Brasil como un ejemplo de la articulación entre historia y estructura, y es un antecedente importante de esa noción, antes citada, de la absorción de la historia por los esquemas simbólicos indígenas (Sahlins 1985).

En términos generales, ese cuadro tiene algo de inconsecuente. Ese juego de asimilación de lo nuevo y alteración de lo conocido, que parece sugerir un perpetuo movimiento de cambio, lleva con frecuencia a interpretaciones más bien conservadoras. Lo único constante en la tradición indígena es su inconstancia (Viveiros de Castro 2002) pero eso puede ser descrito en términos que sugieren una especie de estructura profunda que recuerda a la del estructural-funcionalismo: en su inconstancia, los paradigmas indígenas alcanzan una duración inaudita. Hay una sociedad sin límites precisos, pero hay al fin y al cabo una sociedad, y toda esa abertura y toda esa incerteza son sus atributos. Hay, en fin, una diversidad de sujetos -animales, espíritus, extranjeros- pero todo eso remite en última instancia a los miembros (vivos, humanos, tangibles) de esa sociedad, que son los titulares privilegiados de los simbolismos que el ritual escenifica. Bajo esas reelaboraciones recientes subsiste, por tanto, una imagen fuerte y clásica, diseñada por Durkheim: una sociedad que el ritual realiza en su acepción plena. El relato es, como se ve, convincente y aún vigoroso. ¿Hay algún otro relato posible que sea capaz de integrar elementos excluidos por este? Intentaremos buscarlo en ciertos ángulos ciegos, o al menos periféricos, de la etnografía.

\section{1. ¿Rituales?}

Paul Marcoy fue un viajero cuyas informaciones no han sido tomadas demasiado en serio. Han contribuido a ello sus concesiones a la ficción -su libro más famoso, el Viaje al país de la Quina, puede ser un fraude, y él mismo usaba un pseudónimopero también, quizás, el pintoresquismo a veces burlesco que tienen sus relatos mejor contrastados, en particular el de su estancia (hacia 1846-1848) en la misión de Sarayacu en el Ucayali, donde el Padre Plaza, franciscano, realizaba por su cuenta una empresa evangelizadora que por entonces no contaba con el apoyo de las autoridades 
del Perú independiente. Uno de los episodios que narra (Marcoy 1867: 204-208) ${ }^{2}$ consiste en una parodia de dos visitantes que habían pasado muchos años antes por la misión, los científicos ingleses Smyth y Lowe. Esa parodia formaba parte de una gran fiesta de Navidad y Año Nuevo que unía ceremonias y danzas de muy variada inspiración amazónica, andina e ibérica, etc. Los indios se habían esforzado en imitar el atuendo de los ingleses - ropas pintadas en la piel con urucum y genipa- y en fabricar reproducciones rústicas de sus instrumentos de observación - un octante hecho con una escuadra y un espejo- y medición. Delante de un público que se retorcía de risa -empezando por el misionero, que dio a Marcoy la identificación de los personajesrealizaban su pantomima: Smyth escudriñaba el cielo con sus instrumentos mientras Lowe simulaba tomar notas con una enorme pluma. Marcoy dejó incluso un dibujo, donde representa la función, y donde puede distinguirse la rabelaisiana figura del Padre Plaza disfrutando de la burla. La función traza un triángulo curioso: es la parodia del comportamiento de unos extranjeros, ejecutada por los indios ante otro extranjero de la misma especie y ante un extranjero más próximo, el propio misionero. Marcoy, que nutría un mixto de admiración y repulsión por Plaza, especula que la sátira podría ser una venganza contra dos visitantes que no habían dejado una contribución digna en el cepillo de las limosnas.

Los propios misioneros fueron tratados aún peor unas décadas después, en un lugar próximo a Sarayacu y por nativos de lengua pano, como los que vivían en Sarayacu. Según cuenta el franciscano Lucas Martorell (Amich 1988: 422-427), los amahuaca reunidos por los religiosos en el río Tamaya recibieron con desgana las pretensiones misioneras y, al cabo, reaccionaron con cierta violencia, intimidando a los franciscanos con el fin de apartarlos y también de «profanar los ornamentos del culto divino, haciendo trizas de las mismas casullas y sirviéndose de ellas para sus mojigangas o bailes ridículos». En un rapto de ira, Martorell se explaya:

«Esos miserables chunchos, en su estúpida brutalidad, podrían figurar al lado de los sansculottes de Paris y de los jacobinos franceses de 1793, que bailaban la carmañola con las capas de coro de las Catedrales de aquella cristianísima Nación, y ser dignos compañeros de los Comunistas de la misma París, sus contemporáneos».

El misionero reconoce una parodia carnavalesca, y puede encajarla en una categoría conocida, porque el cristianismo conocía tales mojigangas, coexistiendo con él o integrándose a veces en el propio ritual oficial, como ocurrió durante siglos, por ejemplo, en las celebraciones del Corpus. De hecho, la parodia que narra Marcoy está integrada en una fiesta nominalmente católica, y Martorell se ocupa por sí mismo de tender un puente entre los «bailes ridículos» de los indios y un linaje de «antirituales», parodias blasfemas que tuvieron una función importante en los movimientos revolucionarios del viejo continente (Delgado 1989). Pero esas mojigangas o esos antirituales ¿pertenecen de derecho al mundo del ritual? Lo más común ha sido reducirlos a una dimensión marginal, profana o profanadora del «ritual legítimo»; pero como ya hemos visto antes la parodia de los extranjeros se integra, en el caso

2 Referimos a la primera publicación, en un fascículo del semanario Le Tour du Monde (Marcoy 1867); el relato del viaje de Marcoy (Laurent Saint Cricq en la vida civil) fue publicado después como libro (Marcoy 1869). 
amazónico, en una tradición donde su exótica aparición ya formaba el núcleo de los rituales más centrales.

Siglo y medio más tarde, y con algún sentido del humor, uno de los autores de este texto (Calavia 2004) se propuso describir los rituales yaminawa, superando el obstáculo de que los rituales yaminawa «ya no existían»: se habían perdido como casi todo el ajuar cultural de aquel pueblo reconocidamente ávido de novedades. El resultado fue un tratado sobre el ritual yaminawa dedicado a dos fiestas que podían ser llamadas «rituales» sólo si se cuestionasen los límites corrientes del concepto. A la debida distancia, el autor cree que el concepto puede, sí, abarcar los dos «rituales» que presenció: aquella celebración en la que, entre encendidos discursos del entonces jefe y de su discreto rival que poco después le sucedería en el cargo, se distribuyó entre todos los yaminawa, organizados en dos grandes filas, una enorme caja de bombones que aquel último se había traído de Noruega como presente de una ONG amiga. Y aquella otra en que el nuevo jefe, cantando a la guitarra los éxitos de la música regional, y distribuyendo la bebida con extrema reticencia, consiguió que los yaminawa celebrasen un baile «como los de los blancos». Si los motivos parecen poco «tradicionales», el empeño en coordinar un agregado caótico de seguidores en una coreografía común en torno de acciones significativas hizo de esas ocasiones rituales tan buenos como cualquier otro.

El análisis sugería que el tiempo en que un ritual se torna ritual es mucho más corto de lo que suponemos, que -a despecho de ese arcaísmo que se le supone- hay menos trecho del que se tiende a suponer entre la invención y la consolidación de un ritual. Insistía también en la sombra que la falta de una ritualidad tradicional arrojaba sobre la situación política de los jefes, que necesitarían de esa «cultura» para hacer política fuerte en el contexto regional, y en su empeño por al menos tornar tangible, visible, la sociedad que dirigían o intentaban dirigir. Ese entrecomillado de la «cultura» ha sido propuesto (Carneiro da Cunha 2009) para indicar el uso nativo de un concepto otrora propio de los antropólogos, la objetivación, delimitación y, a veces, patrimonialización de un acervo de artes, usos o saberes tradicionales que se han vuelto estratégicos en un escenario político multiculturalista.

Ahora sería conveniente destacar algunos otros aspectos, citados entonces en segundo plano. El fundamental es que las dos fiestas yaminawa manipulaban exclusivamente elementos del mundo de los blancos y, sobre todo, pretendían asimilar los conceptos y el estilo de acción de los blancos. Esta vez la imitación de los blancos no estaba destinada a la diversión de otros blancos, sino a los propios yaminawa: era un ensayo o una prueba de lo que ellos y sus jefes podía ser capaces de hacer. No eran actuaciones dirigidas a los blancos presentes -yo solo en el primer caso, con la adición de unos seringueiros músicos en el segundo- que no figurábamos allí como público sino como actores. Actores secundarios, aunque quizás claves para dar autenticidad a aquellas fiestas de nuevo cuño. 


\section{Intercambios cósmicos}

De los yaminawa podemos pasar ahora a su opuesto diametral, un pueblo al que los avatares de la situación pre-contacto, y las propias doctrinas y prácticas de contacto del indigenismo brasileño, han definido como una sociedad con límites precisos, con una plétora de signos de identidad de gran valor distintivo -o en otras palabras una «cultura» de peso-: los matis.

Los matis (Erikson 1996; Arisi 2007, 2011) establecieron contacto con la FUNAI entre 1976 y 1978, en un proceso diseñado por el órgano indigenista de un modo que en cierto sentido equivale a ese entrecomillado de la «cultura» del que antes hablábamos. Aunque infelizmente ese celo no impida episodios trágicos de epidemias letales como las que aniquilaron a cerca de dos tercios de los matis en los primeros años, el trato que se dispensa a los llamados «indios aislados» visa un control de su pureza cultural y de su integridad social que lleva a curiosos extremos, sea poniéndoles dificultades para que adquieran ropas (Arisi 2007, 2010), o, años después, velando por que su imagen no sea exotizada explotando, por ejemplo, su desnudez (Arisi 2011). La autenticidad puede cambiar rápidamente de forma. En 2009, un cámara norteamericano mostraba su irritación porque las indias se habían despojado de sus sostenes para la filmación: temía que el público identificase esos pechos al aire como un truco suyo para fingir un tipo de autenticidad ya desacreditado por los consumidores de televisión. Binan Tuku, el primer hombre matis en visitar una ciudad y uno de los más fotografiados, se oponía a las críticas que se habían hecho a la divulgación de una fotografía en que él aparecía «desnudo», o-según su concepto- vestido con el cordón de embira que le amarraba el prepucio: «el pene es mío, lo muestro como quiero y a quien quiero» (Arisi 2011: 512). El hombre que muestra su pene o las jóvenes que muestran los senos no son ingenuos: conocen las expectativas a las que se enfrentan y las manipulan no sin sentido de la comedia.

Los matis, en suma, saben que son exóticos y que a su «auto-denominación» como matsés kimo, que no sería mal traducido como gente auténtica, corresponde el carácter de nawa kimo, o sea extranjeros auténticos o super-extranjeros -diferentes de los brasileños que consideran más próximos- que ellos atribuyen a esos visitantes que les llegan dispuestos a realizar documentales o, simplemente, a convivir con y fotografiar a un pueblo exótico. Esa extranjería eminente llega a su ápice cuando se confrontan, por ejemplo, con los representantes de una televisión surcoreana, en los que, además de esa inequívoca parafernalia de los extranjeros, identifican una sorprendente semejanza física con ellos mismos (Arisi 2011: 468).

Los super-extranjeros perciben también, por supuesto, el exotismo de los matis, y la dificultad que tiene filmarlos - por el arduo acceso a sus aldeas y por las trabas burocráticas brasileñas- convierte un documental realizado entre ellos en un punto fuerte del curriculum de cualquier documentalista. Junto a la exhibición de escenas peculiares de la vida cotidiana -esencialmente la caza con cerbatana y la preparación culinaria de las piezas- el objeto preferente de esos documentales es el ritual. El más común de ellos, por su espectacularidad y su valor icónico, ha sido el de los Mariwin, espíritus de antepasados, o seres de la floresta, que comparecen -paramentados con una máscara de cerámica u hoja coronada por helechos y el cuerpo untado de carbón 
o achiote- para azotar a los vivos - especialmente mujeres, niños y cazadores con mala suerte o puntería- y darles con ello vigor y disposición para el trabajo. Las máscaras de Mariwin, por su escueta expresividad y su facilidad de transporte, se han convertido en la imagen de marca de los matis: no pueden faltar en museos etnológicos o en tiendas de artesanía indígena de las ciudades cercanas, y los propios matis parecen haberlas escogido no sólo como seña de identidad, sino también como prueba de que esa identidad no está atada a la permanencia de un universo arcaico: máscaras de Mariwin hechas con una simple hoja, o con un pedazo de bidón de plástico, son buenas muestras.

Evidentemente, los matis obtienen por medio de su venta de exotismo unos rendimientos que difícilmente obtendrían por medios mucho más penosos -como los que otros grupos buscan entre madereros, garimperos, seringalistas o gateros- y ese móvil económico les lleva a explotar conscientemente su imagen, y a buscar nuevas formas de explotarla o exportarla ${ }^{3}$.

Todo ello podría ser, así, despachado como una consecuencia mercantil más de la globalización, y como una reducción del ritual a commodity. Pero en esa evaluación se revela un juicio viciado. Sólo desde que la actividad económica se transformó en la realidad y la racionalidad indiscutibles se ha hecho posible imaginar, por contraste, un tipo de actividad improductiva, irracional y apartada de todo intercambio económico como podría ser el ritual. Pero los rituales nunca fueron, en la Amazonia o en cualquier otro lugar, ajenos a la economía: son los mismos que toleran viejas celebraciones religiosas en un espacio laico «porque fomentan el turismo» quienes se sorprenden a veces de que sus realizadores -máscaras matis, artesanos o foliões del Carnaval carioca o cofrades de una Semana Santa española- se lucren con ellos. No sólo en la Amazonia las cámaras se insertan en los rituales, y ni en la Amazonia ni en otros lugares eso los falsifica: son los documentales, y no los rituales, los que necesitan esconder el instrumental cinematográfico para preservar su autenticidad.

La racionalidad económica de ese tráfico de símbolos debe ser templada con algunas consideraciones: lo que se obtiene de los super-extranjeros es, para empezar, un conjunto de super-bienes. Por ejemplo, un grupo de turistas alemanes -verdaderos cazadores de exotismo que tenían estampadas en sus pasaportes visitas a islas etnográficamente famosas como Irian Jaya- que llegó para hacer fotos de los matis cazando sin sus camisetas, pagó con ropas hechas de Gore-Tex, material de camping high-tech y linternas con lámparas led. Tales materiales continúan el linaje de las célebres miçangas o cuentas de vidrio (cf. el artículo de Lagrou en este mismo volumen) que no deben ser confundidas con la, digamos, economía profana de la subsistencia cotidiana, que continúa siendo atendida por medios más corrientes. Pertenecen de pleno derecho a una economía suntuaria. Por otra parte, continúan -como quieren los análisis a los que nos referimos al inicio- una serie de intercambios establecidos con otros seres en versiones anteriores de su cosmología. Los matis siguen

\footnotetext{
3 Otro ejemplo interesante de ritual para extranjeros es la danza de los Praiás realizada por los pankararu en las «arenas culturales de São Paulo» (Albuquerque 2011). Los pankararu tienen comunidades en Pernambuco y también en São Paulo. A pesar de que podemos pensarlos como antípodas radicales de los matis, pues tienen que luchar por su reconocimiento como indígenas, las fiestas de máscaras de ambos grupos presentan estrategias muy semejantes de cara a los extranjeros (Albuquerque y Arisi 2012).
} 


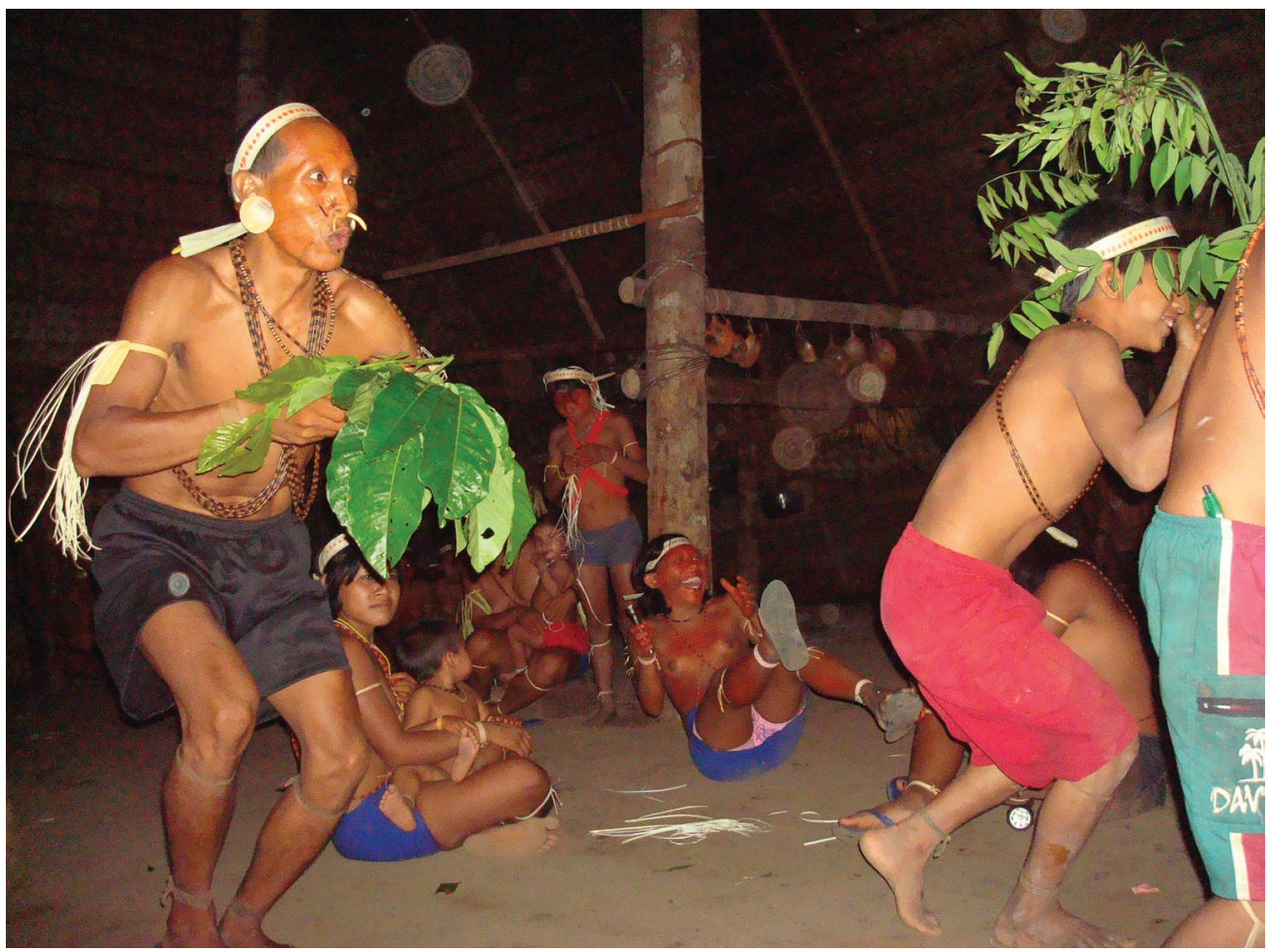

Figura 2: Kuini Marubo Matis inventa un pájaro, el paucar, en la nëix tanek. (Foto de Bárbara Arisi).

realizando en sus casas comunales las nëix tanek (fiestas de animales), donde reciben a una serie de figuras de las que en tiempos míticos obtuvieron -sea como dádiva, sea robándoselos cuando el benefactor era demasiado avaro- ítems fundamentales de su cultura. Así, el jaburu (tuyuyu, Jabiru Mycteria) enseñó a los matis el uso del veneno de pesca y el kampok (vacuna de rana, cf. más adelante); un mono les enseñó las técnicas de tatuaje, otros animales les enseñaron cómo tejer hamacas, o les dieron las principales simientes. Sin embargo, el encuentro con visitantes tan ilustres es un episodio peligroso. Los tapires entran con cuidado para evitar trampas mortales; el primero es capturado y descuartizado ritualmente, para ser cocinado por las mujeres. Cuando entra la bandada de jaburus, uno de ellos es víctima de una anguila eléctrica, y los otros se ponen a salvo subidos a los puntales de la casa. El diálogo de los animales con sus anfitriones busca aclarar las relaciones de parentesco con ellos. Así, el sapo va preguntando si lo encuentran feo (es la respuesta adecuada para los afines) o bonito (la respuesta adecuada para los consanguíneos). Por mucho que se trate de animales míticos, todos esos protocolos pertenecen al mundo, muy real y nunca exento de peligro, de las relaciones sociales. Los matis, que demuestran en las nëix tanek una enorme habilidad para la mímica, traducen el verbo matis tanekin por los verbos «inventar» o «imitar»; la imitación no se opone a la invención. Por el contrario, y al igual que ocurre en las visitas de otro tipo de sujetos, los matis y otros pueblos ama- 
zónicos tienden mediante la imitación (siempre afín a la traducción) un puente con esos extranjeros, e inventan sobre la marcha sus lazos con ellos.

El realismo sociológico que suele aplicarse al análisis de los rituales presupone que todos esos intercambios con animales o espíritus son desarrollos meramente simbólicos de un conjunto mucho más limitado de relaciones reales, o sea intra-aldeanas. Pero esas mismas fiestas que celebran el reencuentro con animales míticos y la capacidad matis para la imitación/invención, al ser contempladas, fotografiadas, filmadas por visitantes aún semidesconocidos, sirven -como motivo pero también como método- para ampliar sus relaciones en dirección al mundo exterior.

\section{La ayahuasca}

La definición sociológica del ritual ha sido el motivo de que el uso de la ayahuasca haya sido habitualmente segregado de esa categoría ${ }^{4}$. La ayahuasca, un brebaje capaz de producir visiones o, en el entender nativo, capaz de establecer contacto entre sus usuarios y otros mundos habitualmente separados -el de los espíritus, el de los muertos, etc.- ocupa un espacio que traduciríamos sin dudarlo mucho como religión. De hecho, y a pesar de la reticencia de los especialistas, esa traducción ha sido extensamente realizada por los propios indios o por sus vecinos, dando lugar a un vasto número de religiones fundadas en la ingestión de la ayahuasca que congregan ya a un número muy considerable de adeptos en los países amazónicos -muy especialmente entre la clase media urbanay más allá de ellos, en los Estados Unidos y en Europa (Labate y Jungaberle 2011). Y sin embargo, los etnógrafos han insistido muchas veces en observar que las sesiones de ayahuasca no son rituales, o no se parecen a nada que pueda llamarse ritual; es el caso de uno de los autores de este artículo, que, mientras buscaba algún tipo de ritual entre los yaminawa, descartó, sin dudarlo, las sesiones de ayahuasca que ellos continuaban celebrando ${ }^{5}$. Esa negativa tiene, o tuvo, su sentido: se trataba de realzar el aspecto técnico, práctico, empírico, de esos usos, evitando el fácil equívoco de entenderlas como una repetición de gestos estereotipados. El uso de ayahuasca que se podía presenciar entre los yaminawa prescindía de todos esos elementos que no dejaban de aparecer incluso en los rituales improvisados de los que antes mencionamos: parlamentos, regulación de la postura y la disposición del espacio. Sobre todo prescindía de escenificaciones colectivas: la ayahuasca era tomada en un ambiente doméstico y reservado -en cierta ocasión los participantes no pasaban de dos-, el brebaje era preparado en un fuego de cocina corriente, y los yaminawa ni siquiera se preocupaban de las restricciones

\footnotetext{
4 El primer informe inequívoco al respecto de la ayahuasca es el de Spruce, publicado originalmente en 1908 pero que relata una experiencia de 1852 (Spruce 2000); Reichel Dolmatoff (1975) está entre los primeros etnólogos que llaman la atención hacia ella. La bibliografía actual sobre la ayahuasca es enorme (Labate et al. 2008; Labate y Jungaberle 2011; Calavia 2011; Losonczy y Mesturini 2011, entre otros). El clásico de Chaumeil (1983) da una excelente visión del lugar de la ayahuasca en un sistema chamánico.

5 Esa opinión, a la vista está, se ha matizado desde entonces. Por lo demás, las sesiones yaminawa tenían una característica notable: solían realizarse en la noche del sábado, asumiendo un esquema temporal que por supuesto era ajeno a la rutina de la aldea, pero que los yaminawa habían adoptado de sus visitas a la ciudad y probablemente de su experiencia anterior en un seringal.
} 
alimentarias que se suelen guardar incluso en los usos más informales ${ }^{6}$. Una vez distribuida la bebida, cada cual se retiraba a su hamaca en la oscuridad, y desde entonces las interacciones entre los participantes se limitaban al encuentro de los cantos con que, sin ningún orden fijo, cada cual acompañaba las visiones que pudiera tener. El resultado -a veces de una belleza musical sobrecogedora- recuerda más al de una jam session que al de un coro religioso. En una de las ocasiones estaba presente un adepto de una de las versiones mestizas de la ayahuasca -el Santo Daime- que contribuyó con las cantigas de su religión, semejantes a las del catolicismo popular brasileño.

Ese tipo de uso extremamente informal de la ayahuasca se presenta frecuentemente en paralelo con otro muy diferente, inscrito en ocasiones festivas. En una corta estancia en 1998 en la aldea indígena yawanawa del Río Gregorio, nos fue dado asistir, casi sin solución de continuidad, a las dos versiones. El mismo día de nuestra llega$\mathrm{da}^{7}$, se nos avisó de que uno de los chamanes del grupo estaba realizando una sesión de cura, y nos invitaba a participar en ella. El mismo mensajero nos condujo entonces a la casa del chamán, a alguna distancia del centro de la aldea, y allí encontramos a éste, al enfermo tendido en el suelo de la cabaña, y a algunos de sus parientes que lo acompañaban. El chamán tomaba la ayahuasca y convidaba a tomarla a quien quisiese. Cualquier participante estaba autorizado a cantar lo que veía, pero el chamán era, obviamente, el más expresivo, y dirigía sus cantos hacia un cuenco de bebida de maíz que el enfermo, dormido durante la mayor parte del tratamiento, acabó tomando. El grado de formalización de la sesión curativa era muy ligeramente superior al de las sesiones sin pretensiones terapéuticas que el autor había presenciado entre los yaminawa. Días después, sin embargo, se realizó una gran fiesta en el centro de la aldea, para contento de los yawanawa pero también en honor de un conjunto de visitantes extranjeros -representantes de varios organismos oficiales, aparte de nosotros mismos, que estábamos allí independientemente- muy interesados en el evento. La ayahuasca fue entonces distribuida por el mismo chamán de la otra noche, e ingerida por un gran número de participantes que acudían en fila a obtenerla. Para el observador, que sólo conocía hasta entonces los usos del primer tipo, fue una novedad ver la ayahuasca en funciones que recordaban las del alcohol, animando a los participantes que, en lugar de recogerse a sus hamacas para acoger visiones, se consagraban a una intensa suite de danzas en medio de una casa colectiva. Las danzas, por cierto, confrontaban dos grupos de afines potenciales: los danzantes no podían ver frente a ellos a sujetos con los que la consanguinidad vedase un eventual matrimonio. En otras ocasiones esa separación se ensanchaba haciendo que los dos grupos actuasen como enemigos, escenificando una guerra con imitaciones de lanzas.

El caso yawanawa es especialmente elocuente por las razones que detallaremos enseguida. Ese tipo de ingestión colectiva está muy extendido en la Amazonia, en general coexistiendo con el uso más privado que hacen de ella los chamanes, y consta que en algunos casos era más común en el pasado (Pérez Gil 2004). No hay cómo

6 Los objetivos de esos cuidados son declaradamente prácticos: reforzar el efecto de la bebida o evitar un exceso de vómitos o diarreas.

7 Óscar Calavia acompañaba en la ocasión a Miguel Carid Naveira y Laura Pérez Gil, que realizaron una investigación de campo más larga en la misma aldea (para otros trabajos resultados de tal pesquisa, ver Calavia et al. 2004). 
atribuir a uno $\mathrm{u}$ otro modo una precedencia temporal, aunque en la medida en que la ayahuasca (cf. Gow 1996) puede haber sido un saber difundido entre los pueblos de la selva a partir de una koiné realizada en el espacio fluvial -en otras palabras, a partir del mismo mundo misionero que conoció Marcoy- es probable que su versión privada e informal, en las casas de los chamanes, esté en muchos casos en el origen de su uso en ocasiones colectivas.

El caso es que esa versión colectiva ha vuelto a ponerse en evidencia a medida que el uso de la ayahuasca ha trascendido las aldeas indígenas, e incluso los espacios de las religiones ayahuasqueras, para convertirse en uno de los motivos centrales de un neochamanismo realizado muy lejos de la Amazonia con la participación directa de los indios -los guarani, los kaxinawá, y sobre todo los yawanawa- como oficiantes (Rose y Langdon 2010; Oliveira 2012) y un público amplio, en general procedente de las clases medias urbanas. En estos casos, la formalización se adecua a los requisitos de un ritual primitivista: disposición de los participantes en círculo, fuego sagrado central sobre el que se hacen pasar objetos, ofrendas o invocaciones dirigidas a los puntos cardinales. Son esas las acciones que la imaginación exótica occidental entiende como propias del ritual originario, una representación del cosmos y de la sociedad. Casi nada de eso formaba parte de los usos indígenas de la ayahuasca, sea en su versión privada o en su versión colectiva, pero no hay duda de que los indios se han apresurado a utilizar todo ese repertorio, tan exótico para ellos como para su público, para abrir un espacio de comunicación.

Lo que proporciona un hilo conductor a todas las versiones de la ayahuasca es, sin embargo, algo que nunca, que sepamos, se ha subrayado: ellas son, siempre, un ejemplo más de esos rituales de visita de los que hablábamos al principio. Los cantos que se entonan incluso en las versiones más recoletas de la ayahuasca son descripciones de tales visitas: tal o cual espíritu está llegando, se le ve venir, se le describe. En las traducciones que Calavia Sáez consiguió obtener -sumarias e inseguras, porque esos cantos chamánicos están expresos en un lenguaje rebuscado, hermético para los traductores no iniciados de que pudo disponer- los cantos parecían algo así como la voz reiterada de un heraldo que va anunciando el nombre y los títulos de los convidados que comparecen a la fiesta. Lo que es más interesante, esas ocasiones que eran «por dentro» visitas visionarias, eran -o fueron- visitas también «por fuera» ${ }^{8}$. La situación prototípica de las sesiones de ayahuasca de los viejos tiempos era, según contaban los yaminawa, la de la reunión entre dos grupos que se buscaban, o simplemente se encontraban en medio de sus andanzas por la selva, y a partir de ahí decidían beber juntos y rivalizar en conocimiento de cantos y espíritus. Esos encuentros, nótese bien, eran, mucho antes de que la ayahuasca se tornase principalmente un medio de cura, encuentros peligrosos, que acababan a veces muy violentamente cuando, por ejemplo, aparecían espíritus de antepasados que azuzaban viejas deudas de sangre entre los participantes. Alfredo, el yaminawa que con más disposición relataba ese pasado, mostraba la cicatriz que aún tenía en la cabeza producto de uno de esos encuentros;

8 Las dos dimensiones no se pueden separar con facilidad. Oliveira (2012) narra algún caso en que espíritus provenientes de las religiones afro-brasileiras - que algunos invitados a las sesiones de chamanismo yawa habían traído evidentemente consigo-interpelan a los titulares indígenas de la ceremonia. 
su padre había sido muerto en esa misma ocasión. Un misionero dominico (Álvarez 1964) narra un episodio especialmente violento ocurrido en esas circunstancias entre un grupo amahuaca y un grupo yaminawa que se habían puesto en contacto en su misión. En la actualidad, la visita visible continúa celebrándose en torno de la visita invisible (o visible sólo por medio de la ayahuasca), con un nuevo tipo de participantes, y desvinculada de la guerra, aunque no necesariamente de alguna competición. Los matis mantienen que el modo de presentarse ante otros tiene un poder que hay que saber medir, pues si se hace con un adorno y una belleza desmesuradas puede incluso matarlos. La belleza es el arma más poderosa que se puede usar en los encuentros, especialmente con extranjeros, sean ellos animales míticos, tsussin o gringos ${ }^{9}$.

Las «vacunas» de secreción de esa rana, común entre grupos pano, llamada en matis de kampok siguen más o menos el mismo camino que la ayahuasca, cada vez más presente en rituales urbanos como los de los katukina pano (Coffaci de Lima 2005). Entre los matis, la vacuna de kampok es una acción reservada al espacio doméstico, para cura y prevención de enfermedades o de la mala suerte en las cacerías. Ocurre lejos de la pompa de fiestas como el nëix tanek o el Mariwin, y por ahora sólo se comercializa su aplicación en forma de filmaciones de periodistas como los de BBC que se atreven a probarla en el mejor estilo reality show; los matis no hacen dinero con tales rituales en centros urbanos como lo hacen los katukina (Arisi 2011: 278).

Sea como sea, la ayahuasca y la vacuna del kampok han servido como hilo de conexión de una vasta red que no sólo conecta religiones sino -y eso muy conscientemente- efectivas alianzas entre grupos indígenas y sectores sociales en principio muy lejanos a la selva. Las clases medias urbanas, cuyos miembros se pueden insertar como participantes de pleno derecho en esa red yawa - nawa (el concepto es de Oliveira 2012) actuando como clientes, intermediarios, aprendices o chamanes de pleno derecho -y por lo tanto como una especie de indios honorarios- suponen un nuevo capítulo en la constitución de un grupo, los yawanawa, que ya inicialmente se constituyó, durante la época del caucho, por la asimilación de etnias muy diferentes. Una vez más, sólo un prejuicio primitivista justificaría que viésemos en todo ese trabajo ritual una mera representación de la simbología de la alteridad: las relaciones establecidas por ese medio son inequívocamente afectivas y efectivas.

\section{Eficacia ritual}

Nuestra comprensión del ritual parte, habitualmente, de su valor representativo: él escenifica la sociedad, con sus jerarquías, sus alianzas o sus conflictos, y lo hace de acuerdo con esquemas preestablecidos. En ese sentido sabemos que nosotros mismos tenemos rituales, muchos, y en ese sentido a muchos de nosotros -es una tradición de nuestra civilización- no nos gustan los rituales, porque son sombras estereotipadas, accionesmáscaras, guiones fijos, pesadas ceremonias que parecen no tener fin. Los rituales se

9 Los matis no toman ayahuasca pero sí tatxik, una bebida hecha a partir de otra liana, que también comparten con sus vecinos korubo y los mayoruna/matsés. La toman también a la noche entre cantos de kamun (jaguar). Los matis advierten que en tales ocasiones la maloca es visitada por tsussin (potencias desincorporadas como sugiere Lagrou 2007) y por gente que puede estar físicamente lejos de la aldea. 
oponen no sólo a la vida real sino también al juego, que cuentan con la indeterminación y la imprevisibilidad. Más allá de nuestras fronteras, los rituales son, además, eficaces, producen: hacen que llueva, o que los niños crezcan, o que las plagas de langostas se alejen, que los cazadores recuperen su suerte o su puntería. Pero eso solamente en las tierras de los otros, porque la única eficacia que nosotros estamos dispuestos a conceder a los rituales es, digamos, tautológica: ellos reafirman las jerarquías, o refuerzan el sentido de unidad, o de pertenencia, o resuelven simbólicamente tensiones estructurales. En suma, revigoran lo ya existente. Los otros, que no están tan imbuidos de ideas durkheimianas, comprenden el ritual comenzando por ese otro lado: lo ejecutan porque es eficaz. Sólo en función de ese objetivo pueden empeñarse en replicar un esquema predeterminado (debe ser hecho correctamente para que sea eficiente) o incluso en su carácter totalizador (hace falta que todos hagan fuerza para que sea eficiente). Es precisamente por no creer en esa eficacia del ritual que tendemos a eliminar de la categoría «ritual» todo aquello que parece remitir más fácilmente a un valor digamos técnico. Es el caso, en el mundo pano, de las sesiones de ayahuasca realizadas por chamanes o semi-chamanes: están sometidas, sí, a un esquema sumario, pero por lo demás son de libre ejecución, y su desarrollo -la participación de los visionarios-cantores, la aparición de tales o cuales espíritus, la mayor o menor duración de la sesión, la conducta visible de los participantes- es imprevisible. Tendemos a reconocer en esa libertad algo que recuerda más a ciertos dominios de nuestra técnica o nuestro arte. La reproducción previsible de las conductas y de su interpretación es la clave del concepto, y por eso las acepciones más amplias del ritual, esas en las que puede caber desde una ceremonia de coronación hasta un apretón de manos, se basan exclusivamente en ella. Poco tiene de extraño: a fin de cuentas, venimos de una tradición que ha codificado de un modo muy rígido las acciones y las interpretaciones, que les ha dado un metasignificado reflexivo, constituyendo una «cultura», un «patrimonio inmaterial» o una «ortodoxia», y que ha tornado todos esos entrecomillados atributos o representaciones de una sociedad que existe: está encarnada en constituciones, atestiguada por carnets de identidad, cuajada en un territorio, etc.

Pero, ¿y si esa «sociedad» no existiese? ¿Qué podrían entonces representar los rituales? Es, quizás, el caso de la Amazonia, pues decir que una sociedad no tiene límites claros equivale, en último término, a decir que ella no existe, al menos de un modo en que pueda designársela con un sustantivo como «sociedad». Si no hay una sociedad, ¿cómo podrían los rituales ser su representación estereotipada? Podrían, claro está, ser la representación estereotipada de relaciones sociales - un término menos sustantivizador que «sociedad»-, pero ¿qué es lo que garantiza en ese caso esa precedencia, qué determina cuál es la realidad y cuál su representación estereotipada? Si empezamos este artículo hablando de la duplicidad de interpretaciones que se da a esa absorción indígena de la cultura foránea, en el curso de sus páginas nos hemos encontrado con otro tipo de duplicidad semejante: los rituales son visitas donde se habla de (y con) visitas. Hacia dentro se alargan para incluir espíritus o antepasados, y hacia fuera integran cineastas, turistas, investigadores o un público que los medios actuales de comunicación tornan virtualmente ilimitado. Y cualquier descripción que se haga de la concepción que los indios tienen de sus relaciones sociales deberá incluir esa expansión que el ritual sirve para efectuar y cualificar: los otros, asimilados 
o conservados con toda su potencia diferencial, forman parte de cualquier cosa que quisiésemos rotular consistentemente como sociedad. Son parte de una «economia cosmolizada» (Arisi 2011: 76), aún más amplia que la globalizada por abarcar todos los actores de un cosmos repleto de animales, ancestros y demás visitas imprevisibles.

Un relato alternativo del ritual podría ensayarse si invirtiésemos la jerarquía lógica que solemos aplicarles: no ya primero las acciones cotidianas de la vida social y después su representación ritual, sino primero las acciones rituales, entendidas como un ensayo de nuevas posibilidades, y después las acciones comunes del día a día que aprovechan las pautas y las relaciones creadas en ocasiones excepcionales por el «ritual».

La idea no es nueva, porque está contenida en la noción de performance; ni sus consecuencias son en rigor nuevas, pues todas las aproximaciones teóricas a las que hemos hecho referencia en el inicio del artículo prevén un margen de reelaboración en todo ese tipo de encuentros, se llamen rituales o no. De hecho no pretendemos ninguna novedad: la etnología de las tierras bajas es rica en teorías innovadoras que, como hacen los indios con las novedades que les llueven del ancho mundo, son domesticadas para que produzcan descripciones razonablemente conservadoras. En ellas, y ese es nuestro punto, ha tenido poco lugar toda esa molesta proliferación de inautenticidad que supone la venta de rituales para la televisión, la adaptación de estilos musicales o festivos, o, incluso, el inefable sentido indígena de la comedia. O lo ha tenido precisamente para mostrar que en él, pese a todo, se reafirma la constancia de una sociedad o una cultura -reputadas, en teoría, como moldes demasiado rígidos para contener esa experiencia-. Sugerimos aquí la posibilidad de entender los rituales como acciones «de laboratorio». Es decir, como ocasiones de establecer relaciones nuevas -modos nuevos de relación si se quiere- que serán eventualmente aprovechados en la vida cotidiana o pasarán a formar parte de la política y la economía corriente, pero que antes de ello pueden ser probadas en un contexto especial, delimitado por signos que advierten a todos de que lo que se hará, se dirá y se verá no debe ser confundido con la realidad común; es, por lo pronto, meta-realidad o sobre-realidad. Para usar un ejemplo ilustre, el ritual puede ser como esa pieza teatral que Hamlet hace ejecutar ante la corte de Dinamarca: puede representar episodios que ya han ocurrido, pero su objetivo principal es ensayar efectos en las relaciones, tal vez crear relaciones nuevas -en ese caso, como sabemos, muy luctuosas- en la vida real. Cuando decimos que la performance de la «cultura» indígena obedece a un nuevo tipo de relación entre indios y extranjeros establecida en un nuevo (ya no tan nuevo) contexto multicultural, parece como si esa nueva relación hubiese sido definida en algún tipo de parlamento o seminario interétnico para después ser puesta en práctica en la escena ritual. Sabemos que, en la mayor parte de los casos, es exactamente lo contrario lo que ha ocurrido: es la ejecución de viejas escenas ante un público nuevo la que da pistas a ambos actores para definir nuevas alianzas o nuevos esquemas simbólicos. 


\section{Referencias bibliográficas}

Albert, Bruce y Alcida Rita Ramos, eds.

2002 Pacificando o branco. Cosmologias do contato no Norte-Amazônico. São Paulo: Editora da UNESP.

Albuquerque, Marcos Alexandre S.

2011 O regime imagético Pankararu. Tradução intercultural na cidade de São Paulo. Tesis de Doctorado. Universidade Federal de Santa Catarina.

Albuquerque, Marcos Alexandre S. y Barbara M. Arisi

2012 «O regime da economia da cultura indígena no Brasil: performances Matis (AM) e Pankararu (SP)». Ponencia presentada en la $28^{a}$ Reunião Brasileira de Antropologia. São Paulo.

Álvarez, Ricardo

1964 «Ícaros: crimen y venganza». Misiones Dominicanas 45 (267): 20-25.

Амich, José

1988 Historia de las misiones del convento de Santa Rosa de Ocopa. Iquitos: CETAIIAP.

Agostinho, P.

1974 Kwarip, mito e ritual no Alto Xingu. São Paulo: EPU.

ARISI, Barbara M.

2007 Matis e Korubo: contato e índios isolados no Vale do Javari, Amazônia. Tesis de Maestría. Universidade Federal de Santa Catarina.

2010 «Matis y korubo, contacto y pueblos aislados: narrativas nativas y etnografía en la Amazonia brasilera». Revista Mundo Amazónico 1: 41-64.

2011 A dádiva, a sovinice e a beleza. Economia da cultura Matis, Vale do Javari, Amazônia. Tesis de Doctorado. Universidade Federal de Santa Catarina.

BOROFSKY, Robert

1996 Making History: Pukapukan and Anthropological Constructions of Knowledge [1987]. Cambridge: Cambridge University Press.

1997 «Cook, Lono, Obeyesekere, and Sahlins». Current Anthropology 38 (2): 255-282.

Calavia SÁez, Óscar

2002 «Nawa Inawa». Ilha 4 (1): 35-57.

2004 «In Search of Ritual: Tradition, Outer World and Bad Manners in the Amazon». The Journal of the Royal Anthropological Institute 10 (1): 157-173.

2011 «A Vine Network», en The Internationalization of Ayahuasca, Beatriz C. Labate y Henrik Jungaberle, eds., pp. 131-144. Zurich: Lit Verlag.

Calavia SÁez, Óscar, Miguel Carid Naveira y Laura Pérez GiL

2003 «O saber é estranho e amargo. Sociologia e mitologia do conhecimento entre os Yaminawa». Revista Campos 4: 9-28.

Carneiro Da Cunha Manuela

2009 «'Cultura' e cultura: conhecimentos tradicionais e direitos inteletuais», en Cultura com aspas, pp. 311-373. São Paulo: Cosac \& Naify. 
Chaumeil, Jean Pierre

1983 Voir, savoir, pouvoir: le chamanisme chez les Yagua du nord-est peruvien. París: Editions de l'École des Hautes Etudes en Sciences Sociales.

Coffaci De Lima, Edilene

2005 «Kampu, kampô, kambô: os usos do sapo verde entre os Katukina». Revista do IPHAN 32: 254-267.

Delgado Ruiz, Manuel

1989 «La antirreligiosidad popular en España», en La religiosidad popular, I: antropología e historia, Carlos Álvarez Santaló, Ma Jesús Buxó i Rey y Salvador Rodríguez Becerra, coords., pp. 499-514. Barcelona: Anthropos.

ERIKSON, Philippe

1996 La Griffe des Aïeux marquage du corps et démarquages ethniques chez les Matis d'Amazonie. París: Peeters.

Gow Peter

1996 «River people: Shamanism and History in Western Amazonia», en Shamanism, History and the State, Nicholas Thomas y Caroline Humphrey, eds., pp. 90-113. Ann Arbor: The University of Michigan Press

HowArD, Catherine V.

1993 «Pawana: a farsa dos 'visitantes' entre os Waiwai da Amazônia setentrional», en Amazônia: etnologia e história indígena, Manuela Carneiro da Cunha y Eduardo Viveiros de Castro, orgs., pp. 229-264. São Paulo: NHII-USP/FAPESP.

JunQueIRA, Carmen y Vaneska Taciana VitTi

2009 «O Kwaryp kamaiurá na aldeia de Ipavu». Estudos Avançados 23 (65): 133-148.

LABATE, Beatriz C., Isabel de Rose y Rafael Guimarães dos SAntos

2008 Religiões ayahuasqueiras: um balanço bibliográfico. Campinas: Mercado de Letras.

Labate, Beatriz C. y Henrik Jungaberle, eds.

2011 The Internationalization of Ayahuasca. Zurich: Lit Verlag.

LAgrou, Els

2007 A fluidez da forma: arte, alteridade e agência em uma sociedade amazônica (Kaxinawa, Acre). Rio de Janeiro: TopBooks.

Losonczy, Anne-Marie y Silvia MEsturini

2011 «Por que a ayahuasca. Da internacionalização de uma prática ritual ameríndia». Anuário Antropológico 2010/I: 9-31.

Marcoy, Paul.

1867 «Voyage à travers l'Amérique du Sud, de l'Océan Pacifique a l'Océan Atlantique», en Le Tour Du Monde: nouveau journal des voyages, M. Edouard Charton, ed. París: Librarie de L. Hachette.

1869 Voyages à travers l'Amérique du Sud de l'Océan Pacifique à l'Océan Atlantique. París: Hachette.

OBEYESEKERE, Gananath

1997 The Apotheosis of Captain Cook: European Mythmaking in the Pacific [1992]. Princeton: Princeton University Press. 
OliveIRA, Aline Ferreira

2012 Yawa-nawa: alianças e pajés nas cidades. Tesis de Maestría, Programa de PósGraduação em Antropologia Social, Universidade Federal de Santa Catarina.

PÉREZ GiL, Laura

2004 «Chamanismo y modernidad: fundamentos etnográficos de un proceso histórico», en Paraíso abierto, jardines cerrados. Pueblos indigenas, saberes y biodiversidad, Óscar Calavia Sáez, Marc Lenaerts y Ana María Spadafora, orgs., pp. 201224. Quito: Abya-Yala.

Reichel-Dolmatoff, Gerardo

1975 The Shaman and the Jaguar: A study of Narcotic Drugs among the Indians of Colombia. Filadelfia: Temple University Press.

Rose, Isabel S. y Esther J. LANGDON

2010 «Diálogos (neo)xamânicos: encontros entre os Guarani e a ayahuasca». Tellus 18: 83-114.

SAHLINS, Marshall.

1985 Islands of History. Chicago: The University of Chicago Press.

1995 How 'Natives' Think: About Captain Cook, For Example. Chicago: The University of Chicago Press.

SiLVA, Márcio

1998 «Masculino e feminino entre os Enawene-Nawe». Sexta-Feira 2: 162-173.

SPRUCE Richard

2000 «On Some Remarkable Narcotics of the Amazon Valley and Orinoco», en Ayahuasca Reader, Luis Eduardo Luna y Steven White, eds., pp. 83-86. Santa Fe: Synergetic Press.

VILAÇA, Aparecida

1992 Comendo como gente: Formas do canibalismo Wari'(Pakaa Nova). Rio de Janeiro: ANPOCS.

Viveiros de Castro, Eduardo

1996 «Os pronomes cosmológicos e o perspectivismo ameríndio». Mana 2 (2): 115144.

2002 A inconstância da alma selvagem e outros ensaios de antropologia. São Paulo: Cosac \& Naify. 